\begin{tabular}{|l|l|l|l|l|l|l|}
\hline InterteXto & Uberaba & UFTM & $\begin{array}{l}\text { v. 3 } \\
\text { n. 2 }\end{array}$ & p. 62-81 & 2010 - jul. / dez. & ISSN 1981-0601 \\
\hline
\end{tabular}

\title{
CALVINO E DRUMMOND: UM OLHAR SOBRE AS CIDADES
}

\section{CALVINO E DRUMMOND: UM OLHAR SOBRE AS CIDADES}

\section{Danielle de Almeida Menezes ${ }^{1}$}

Resumo: A partir de uma leitura comparativa das obras As Cidades Invisíveis, de Ítalo Calvino, e do poema "Edifício Esplendor", de Carlos Drummond de Andrade, este artigo objetiva problematizar a situação do homem moderno em meio à transformação e crescimento desenfreado dos centros urbanos. Apesar de tal crescimento variar, visto que os contextos possuem características que lhes são peculiares, faz-se possível perceber a existência de aspectos semelhantes durante o processo, os quais independem dos espaços urbanos em si. Drummond e Calvino fazem o que Bueno (2002, p.233) classifica como "exame atento e cuidadoso, irônico e amoroso, racional e sensível, da condição humana vivida no contexto da cidade e da metrópole capitalista e contemporânea". Os escritores conseguem lançar um olhar distanciado sobre realidade, como se dela não fizessem parte. Este distanciamento torna-se essencial para que sejam capazes de perceber detalhes discretos da vida moderna no século XX.

Palavras-chave: Modernismo; cidades; comparação; modificação; Calvino; Drummond.

\begin{abstract}
Based on the comparative reading of the works Invisible Cities, written by Ítalo Calvino, and the poem "Edifício Esplendor", by Carlos Drummond de Andrade, this article aims at problematizing the situation of the modern man amid the unbridled transformation and growth of urban centers. Despite the fact that such growth varies, since contexts pursue their peculiar features, it is possible to notice the existence of similar aspects during the growth process, which do not depend on the urban spaces themselves. Drummond and Calvino do what Bueno (2002, p.233) classifies as "the attentive and careful, ironic and loving, rational and sensitive examination of the human condition in the context of the capitalist and contemporary city and metropolis". The authors are able to keep a distant look over reality, as if they were not part of it. Such detachment of reality becomes essential to make them observe slight details of modern life in the twentieth century.
\end{abstract}

Key-words: Modernism; cities; comparison; modification; Calvino; Drummond.

\section{Introdução}

O modernismo foi um fenômeno essencialmente urbano. Já no início do século $X X$, os artistas se viam atraídos pela cidade e esta não era somente

\footnotetext{
${ }^{1}$ Doutora em Estudos da Linguagem pela PUC/RJ. Professora adjunta da UFTM - Universidade Federal do Triângulo Mineiro.dani_menezes@oi.com.br
} 


\begin{tabular}{|l|l|l|l|l|l|l|}
\hline InterteXto & Uberaba & UFTM & $\begin{array}{l}\text { v. 3 } \\
\text { n. } 2\end{array}$ & p. 62-81 & 2010 - jul. / dez. & ISSN 1981-0601 \\
\hline
\end{tabular}

uma questão de opção entre a vida no campo e a vida urbana. No século $X X$, a sociedade efetivamente mudou, tornou-se tecnológica e não havia mais como fugir dessa realidade. A cidade tornou-se, assim, uma metáfora dessa nova ordem social.

Como define Berman (1992, p. 15), "ser moderno é encontrar-se em um ambiente que promete aventura, poder, alegria, crescimento, autotransformação e transformação das coisas ao redor - mas ao mesmo tempo ameaça destruir tudo o que temos, tudo que sabemos, tudo o que somos". Este ambiente que estimula e, paradoxalmente, ameaça o homem, é a cidade moderna. Pode-se pensar, portanto, que ser moderno é estar na cidade moderna, a qual, ao mesmo tempo em que define os indivíduos, é por eles definida. Desse modo, parece pouco provável desvencilhar o homem moderno do seu ambiente, da sua cidade; um compõe o outro e é parte do outro. Contudo, por vezes, essa união não é pacífica, causando o que se convencionou chamar de "mal estar na metrópole moderna e contemporânea" (cf. Bueno, 2002, p. 213).

Esse mal estar parece resultado da instauração de uma ordem capitalista que, ao promover a expansão das sociedades urbanas e industriais, produziu também um sentimento de inconformidade, insatisfação: quanto mais se tem, mais se quer; quanto mais se conhece, mais se percebe que há ainda muito a saber; quanto mais gente por perto, mais sozinho se está. Como define Argan (1998, p. 258-259), no mundo todo, as grandes cidades são "um organismo economicamente passivo e politicamente ingovernável, perigoso para a saúde física e psicológica dos habitantes". Ele aponta que dentro da própria cidade há "impulsos antiurbanos", ela se faz e se destrói, quer dizer, ao mesmo tempo em que a sua função primária é ser ponto de encontro a fim de agregar os cidadãos, mais ela os afasta. Esse afastamento das pessoas resulta da própria expansão das cidades. Por causa disso, tem-se a impressão de que no mundo moderno tudo é caos, contraditório e cabe ao homem tentar distinguir o que no caos não é caos, adequar-se à instabilidade dos 


\begin{tabular}{|l|l|l|l|l|l|l|}
\hline InterteXto & Uberaba & UFTM & $\begin{array}{l}\text { v. 3 } \\
\text { n. } 2\end{array}$ & p. 62-81 & $2010-$ jul. / dez. & ISSN 1981-0601 \\
\hline
\end{tabular}

sentimentos, das coisas e pessoas ao redor.

Portanto, com base nos pressupostos supracitados acerca da experiência urbana na modernidade, neste artigo, objetiva-se descrever como estão presentes no livro As Cidades Invisíveis, de Ítalo Calvino (2003), e no poema "Edifício Esplendor", de Carlos Drummond de Andrade, a problemática da estruturação (explosão) das cidades modernas e a questão do indivíduo neste "emaranhado das existências humanas" (Calvino, 2000, p. 85) que é a cidade moderna, visto que, segundo Berman (1992, p. 53), "ser moderno é fazer parte de um universo (...) onde 'tudo que é sólido desmancha no ar'”. Por uma questão metodológica, a coluna vertebral que sustentará o trabalho será o romance de Calvino.

\section{Análise: um olhar sobre as obras}

As Cidades Invisíveis pode ser lido como um jogo para o qual Calvino convida o leitor a fim de com ele desvendar o que há por trás da constituição das cidades modernas. O viajante veneziano Marco Polo narra ao ouvinte Kublai Khan, imperador dos tártaros, suas visitas às cidades do império de Kublai. Por meio das descrições, é possível viajar com os personagens por locais improváveis, mas, paradoxalmente, reveladores da realidade. As imagens oníricas evocadas pela leitura da obra são, na verdade, metáforas e metonímias. Em outras palavras, a obra trabalha com mundos imagináveis que apontam para mundos reais. Calvino constrói narrativas descritivas de cidades que se entrelaçam, se encadeiam não pelos traços comuns que possuem, mas pelos que dissimulam, num processo de continuidade e descontinuidade. São cidades que se desdobram, que apresentam sua dupla imagem, mostrando muitas vezes o seu contrário. Cada cidade possui algo para revelar, mundos utópicos que são descortinados quando se observa atentamente os pequenos detalhes, buscando respostas nas entrelinhas e ambiguidades. Gradualmente, as pequeninas histórias cingem elementos do mundo moderno, e suas imagens começam a ganhar cor, conforme os olhos de Marco Polo se movem no tempo 


\begin{tabular}{|l|l|l|l|l|l|l|}
\hline InterteXto & Uberaba & UFTM & $\begin{array}{c}\text { v. } 3 \\
\text { n. } 2\end{array}$ & p. 62-81 & 2010 - jul. / dez. & ISSN 1981-0601 \\
\hline
\end{tabular}

e no espaço. Questões modernas, como o inchaço das cidades e o valor descartável das coisas, estão presentes na obra. Por isso, talvez seja possível dizer que este livro é uma meta-obra sobre as cidades, já que a partir da descrição de cidades impossíveis, percebem-se as cidades que são possíveis.

As Cidades Invisíveis é um livro organizado em nove blocos, que podem ser entendidos como capítulos, nos quais há breves descrições de diferentes cidades. No primeiro e no último capítulos, há dez destes pequenos textos e, nos demais capítulos há apenas cinco em cada. Existem onze grupos de cidades e cada grupo engloba cinco descrições de cidades divididas aleatoriamente em cada bloco ou capítulo. Os onze grupos de cidades são: As cidades e a memória; As cidades e o desejo; As cidades e os símbolos; As cidades delgadas; As cidades e as trocas; As cidades e os olhos; As cidades e o nome; As cidades e os mortos; As cidades e o céu; As cidades contínuas e, finalmente, As cidades ocultas. Esse agrupamento evidencia um fio condutor entre as narrativas, apesar de elas serem independentes e passíveis de deslocamento dentro da obra sem prejuízo da compreensão. A obra torna-se imprecisa, mas esta imprecisão só é possível porque as inúmeras partes que a compõem são bem descritas. Como o livro pode começar a ser lido a partir de qualquer ponto, entende-se que ele não possui claramente um início e um fim, ficando a cargo do leitor a decisão por onde começar. É como se alguém estivesse diante de uma reta matemática, da qual se tem contato apenas com um recorte feito por Calvino. Embora as extremidades deste recorte apontem para o infinito, as partes do recorte são finitas. Percebe-se, então, que todo o livro está organizado numa lógica matemática, geométrica, que o próprio Calvino, no ensaio "Exatidão" de Seis propostas para o próximo milênio, assume como seu tipo de escrita preferido:

Queria Ihes falar de minha predileção pelas formas geométricas, pelas simetrias, pelas séries, pela análise combinatória, pelas proporções numéricas, explicar meus escritos em função de minha fidelidade a uma idéia de limite, de medida... Mas quem sabe não será precisamente essa idéia 


\begin{tabular}{|l|l|l|l|l|l|l|}
\hline InterteXto & Uberaba & UFTM & $\begin{array}{l}\text { v. 3 } \\
\text { n. } 2\end{array}$ & p. 62-81 & 2010 - jul. / dez. & ISSN 1981-0601 \\
\hline
\end{tabular}

de limite que suscita a idéia das coisas que não têm fim, como a sucessão de números inteiros numa reta euclidiana? (Calvino, 2000, p. 82)

No mesmo ensaio, o autor descreve a exatidão como: "1) um projeto de obra bem definido e calculado; 2) a evocação de imagens visuais nítidas, incisivas, memoráveis (...); 3) uma linguagem que seja a mais precisa possível como léxico e em sua capacidade de traduzir as nuanças do pensamento e da imaginação" (Calvino, 2000, p. 71-72). Ao descrever o conceito de exatidão, Calvino dá pistas de como a obra "As Cidades Invisíveis" foi composta.

Ainda no ensaio supracitado, Calvino chama atenção para as imagens do cristal e da chama, que, segundo ele, são "duas formas de beleza perfeita da qual o olhar não consegue desprender-se" (p.85). Essa dicotomia do cristal e da chama associa-se à dicotomia "exatidão e imprecisão" e estão presentes noutro símbolo, maior e mais complexo, a cidade ("tensão entre racionalidade geométrica e emaranhado de existências humanas", p.78). Ao mesmo tempo em que as cidades são cristal, pois seguem um projeto arquitetônico, são chama, pois há vida dentro desse projeto, elas não são estáticas, há a presença humana que tudo transforma. A cidade sem chama morre, inexiste, como é possível perceber na descrição da cidade Zora que "obrigada a permanecer imóvel e imutável para facilitar a memorização, definhou, desfezse e sumiu. Foi esquecida pelo mundo" (Calvino, 2003, p. 22). De acordo com Gomes (1994, p. 41), Marco Polo representa a imagem da chama enquanto Kublai Khan representa a imagem do cristal, como é possível depreender deste fragmento:

"- Todavia - dizia -, sei que o meu império é feito com a matéria dos cristais, e agrega as suas moléculas seguindo um desenho perfeito (...). Por que as suas impressões de viagem se detêm em aparências ilusórias e não colhem esse processo irredutível? Por que perder tempo com melancolias não essenciais? Por que esconder do imperador a grandeza de seu destino?

E Marco: - Ao passo que mediante o seu gesto as cidades 


\begin{tabular}{|l|l|l|l|l|l|l|}
\hline InterteXto & Uberaba & UFTM & $\begin{array}{l}\text { v. 3 } \\
\text { n. } 2\end{array}$ & p. 62-81 & 2010 - jul. / dez. & ISSN 1981-0601 \\
\hline
\end{tabular}

erguem muralhas perfeitas, eu recolho as cinzas das outras cidades possíveis que desaparecem para ceder-lhe o lugar (...). Somente conhecendo o resíduo da infelicidade é que se pode computar o número exato de quilates que o diamante final deve conter, para não exceder o cálculo do projeto inicial". (Calvino, 2003, p.60)"

Marco, com sua capacidade de narrar e riqueza de detalhes, dá vida, movimento às cidades do império, o qual, para Kublai, se reduz a um tabuleiro de xadrez (cf. Calvino, 3003, p.115). Marco Polo constrói com clareza combinações da lógica com a imaginação. Ele fala de cada cidade com intimidade e peculiaridade, entretanto, enquanto para ele o contato com as cidades, e com cada uma em particular, torna-se uma vivência, já que há um processo mental que é retomado pelo inconsciente quando narrado, para o ouvinte/ leitor, esta vivência de Marco é convertida em uma experiência de choque, pelo menos em princípio, pois por mais peculiaridades que cada cidade ofereça, todas se misturam no imaginário do leitor e se torna praticamente impossível diferenciá-las. Partindo do pressuposto que Calvino convida o leitor a jogar, nota-se que sua intenção realmente é essa: brincar com o imaginário das pessoas. Por isso, num primeiro momento, o leitor fica meio perdido, em estado de choque, porque não domina as regras do jogo. Porém, ao longo do processo de leitura, essa experiência deixa de ser uma experiência de choque e passa a ser uma experiência do jogo. Há toda uma ordenação que é percebida quando se começa a jogar, regras em meio ao caos aparente que inserem o leitor numa ordem única, da qual só se tem conhecimento quando se faz parte. Essa ordem única é realmente parecida com a que rege as grandes cidades. Cada uma possui um conjunto de regras próprias, que só são conhecidas quando se está na cidade. Toda cidade grande, num primeiro instante, comporta-se, aos olhos de quem vê, de forma labiríntica, mas quanto mais ela é experienciada, experimentada, mais as regras que a compõe passam a ser compreendidas e incorporadas.

Ainda no tocante às imagens do cristal e da chama, propostas por 


\begin{tabular}{|l|l|l|l|l|l|l|}
\hline InterteXto & Uberaba & UFTM & $\begin{array}{c}\text { v. } 3 \\
\text { n. } 2\end{array}$ & p. 62-81 & $2010-$ jul. / dez. & ISSN 1981-0601 \\
\hline
\end{tabular}

Calvino em "Exatidão" e exemplificadas nas Cidades Invisíveis, é interessante perceber que todas as cidades de Calvino possuem nomes de mulher. Por um lado, pode-se pensar que esta escolha do autor esteja relacionada a uma possível idéia de complementariedade: ao lado de toda racionalidade geométrica, explicável pela lógica, há a subjetividade da presença feminina. Por outro lado, a questão parece também remeter ao pensamento platônico que valoriza o céu (considerado masculino) e despreza a terra (feminino) (cf. Melo e Souza, $2002^{2}$ ). Se a verdade, numa perspectiva platoniana, se encontrava num nível supra-celeste, no espírito, no intelecto, tudo que estivesse ligado à terra, à matéria, não deveria ser considerado. Todavia, há de se refletir que não existe a idéia de céu sem a idéia de terra, a noção de masculino só existe em oposição à noção de feminino, logo, a imagem do cristal está intimamente ligada à imagem da chama. Em outras palavras, aliada à racionalidade e ordem geométrica estabelecida (cristal/ masculino), ao planejamento, está a chama (feminino), o fogo, o não planejado. Assim, o não planejado é representado na obra de Calvino pela presença do nome de mulheres, mulheres / cidades que são sedutoras, irresistíveis, que desnorteiam, fazendo a razão perder-se. As cidades descritas possuem um fortíssimo apelo sensual. Frequentemente, ao falar delas, Marco Polo utiliza verbos como invadir, penetrar, ocupar, visitar, entre outros, que parecem comparar as cidades descritas (imaginárias) e, provavelmente, as reais também, à figura de uma meretriz. Será possível pensar as grandes cidades desta forma? Talvez sim, uma vez que, assim como as meretrizes oferecem prazer e riscos ao mesmo tempo, toda grande cidade está sempre disposta a diferentes migrações, possui uma grande rotatividade de pessoas, precisa de investimentos para manter-se e apresenta muitas armadilhas para imigrantes despreparados e ingênuos. Em suma, Calvino parece entender as cidades

\footnotetext{
${ }^{2}$ MELO e SOUZA, Ronaldes de. Notas da disciplina "Literatura Brasileira II", ministrada no segundo semestre de 2002, na Faculdade de Letras - UFRJ.
} 


\begin{tabular}{|l|l|l|l|l|l|l|}
\hline InterteXto & Uberaba & UFTM & $\begin{array}{l}\text { v. 3 } \\
\text { n. } 2\end{array}$ & p. 62-81 & 2010 - jul. / dez. & ISSN 1981-0601 \\
\hline
\end{tabular}

modernas em termos de uma meretriz disposta a atender novos clientes.

Além disso, como se observa a partir de sua organização, As Cidades Invisiveis se mostra uma obra fragmentada, já que se trata da composição de pequenas descrições de cidades. Deste modo, a fragmentação textual pode ser uma metáfora e uma metonímia da cidade real, da metrópole, que, nas palavras de Gomes (1994, p. 27), "resiste à totalização neste universo descontínuo, que se encaminha para o ilegível". Neste ponto, ao considerar também o poema "Edifício Esplendor", cita-se Bueno (2002, p. 213) quando diz que

o termo alienação designa muito da experiência urbana, moderna e contemporânea. (...) Tem sido usado para indicar as crises e conflitos dos sujeitos sociais cindidos, fragmentados, sem raízes, muitas vezes expostos à violência de uma vida cotidiana burocrática e impessoal, que parece ir muito além de qualquer entendimento ou controle humanos. Alheios a si mesmos e distanciados do mundo urbano que não reconhecem como seu, mas como algo separado, estranho e hostil, esses sujeitos sociais certamente viveram, e continuam vivendo, formas diversas do que podemos chamar mal-estar na metrópole moderna e contemporânea criada pelo capitalismo $(\ldots)^{3}$

Em "Edifício Esplendor", observa-se que a fragmentação citadina influi profundamente na figura humana, causando mal-estar e fazendo com que o eu-lírico do mostre-se, à semelhança do caos urbano, fragmentado, dada a dificuldade em se estabelecer uma relação de união entre o que se foi e aquilo que se é, como se existissem dois mundos, duas vidas diferentes e opostas: "Oh que saudades não tenho/ de minha casa paterna./ Era lenta, calma, branca,/ tinha vastos corredores". A partir disto, nota-se que no mundo moderno do eu-lírico - percebido como múltiplo, fragmentário, enervante tudo é rápido, agitado, nervoso, não existe mais monotonia, não há espaços vastos, há cubículos nos quais as pessoas se amontoam. Nessa confusão

\footnotetext{
${ }^{3}$ Grifos do autor.
} 


\begin{tabular}{|l|l|l|l|l|l|l|}
\hline InterteXto & Uberaba & UFTM & $\begin{array}{c}\text { v. } 3 \\
\text { n. } 2\end{array}$ & p. 62-81 & $2010-$ jul. / dez. & ISSN 1981-0601 \\
\hline
\end{tabular}

entre o que se foi e o que se é, perde-se a noção do que se poderá ser, do futuro: “Ah!, o corpo, meu corpo,/ que será do meu corpo?". Para Bueno (2002, p. 214), devido à resistência do real no presente, surge um impulso de reagir. Por causa disso, idealiza-se a serenidade do passado ou a possibilidade de salvação do futuro. No poema, o eu-lírico parece estar numa crise ainda maior que a descrita por Bueno, visto que, embora ele, de alguma forma, idealize o passado, parece não ter esperança redentora alguma no futuro, não tem noção daquilo que ele lhe reserva. Por conta desta falta de adaptação ao presente e incerteza quanto ao futuro, Gomes (1994, p. 29) aponta que

o traço fundamental do homem urbano se define em termos de
um eu fragmentado. No curso de sua vida, ele se torna uma
espécie de estrangeiro, que não se adapta à moldura familiar
de identidade, à aparente fixidez social, mas passa
necessariamente por uma experiência não linear, não
seqüencial.

Esta "experiência não seqüencial" parece ser o que acontece com o eulírico de "Edifício Esplendor", num sentido micro, e em As Cidades Invisíveis, num sentido macro, possivelmente como uma alusão tanto ao processo de urbanização e crescimento das cidades quanto à questão da memória histórica das cidades. Porém, vale ressaltar que, no poema, o eu-lírico sabe que o passado já passou, embora ele esteja presente em sua memória. No livro, esta experiência não sequencial é ainda mais forte, pois a imagem do que poderia ser passado e o que é presente se mesclam, estão juntas a um tempo só. Ao falar de Zaíra, por exemplo, Marco Polo diz que "a cidade é feita das relações entre as medidas de seu espaço e os acontecimentos do passado (...). Uma descrição de Zaíra como é atualmente deveria conter todo passado de Zaíra. Mas a cidade não conta o seu passado, ela o contém como as linhas da mão" (pp.15-16). Tal experiência, como se depreende da citação, revela que as marcas do passado estão inscritas na cidade e compõem a sua paisagem. A cidade se modifica, e isso faz parte de um processo contínuo, mas determinados traços e características permanecem inscritos na cidade. 


\begin{tabular}{|l|l|l|l|l|l|l|}
\hline InterteXto & Uberaba & UFTM & $\begin{array}{l}\text { v. 3 } \\
\text { n. } 2\end{array}$ & p. 62-81 & 2010 - jul. / dez. & ISSN 1981-0601 \\
\hline
\end{tabular}

Conforme Argan (1998, p. 74-75), "a cidade moderna (...) reflete o conceito de uma cidade que (...) continua a mudar sem uma ordem providencial e que, portanto, exatamente a sua mudança contínua é representativa, de modo que o que resta do antigo é interpretado como pertencente à história". Deste modo, observa-se que a cidade irreal de Marco Polo comporta-se da mesma forma que as cidades reais, uma vez que também as grandes cidades estão em mudança contínua e perpétua. Por isso, não há uma cidade de ontem e uma de hoje, há momentos de cidade. Logo, as cidades são compreendidas nos diferentes momentos que as compõem.

Contudo, uma vez que a obra se propõe a ser a metonímia de algo mais complexo que é a cidade real, não se torna possível trabalhar com a idéia de que a história das cidades divide-se em dois tempos claramente definidos: presente e passado. Tanto passado como presente são noções relativas. Não existe, no texto de Calvino, a noção de ruptura entre presente e passado. Entretanto, há a noção de memória histórica, de memória da cidade. Por mais que existam diferentes momentos de cidade, cada momento está contido dentro do outro. Vive-se, por conta disto, numa contradição, pois embora exista certa propensão para que os momentos sejam repetidos (cf. Gomes, 1994, p. 44), é impossível que eles (re)aconteçam exatamente da mesma forma, visto que cada um é único.

A referida impressão de que os momentos podem ser repetidos parece estar ligada ao fato de que a mudança humana é mais lenta que a mudança das cidades. A modificação do homem é mais demorada devido ao fato de que ela é acarretada pela alteração do espaço. Em resumo, Os cenários mudam mais rápido que os personagens, daí a noção de que certos traços permanecem, na intensa e contínua mutação sofrida pelas cidades. Esta idéia parece estar presente quando Polo descreve Melânia:

A população de Melânia se renova: os dialogadores morrem um após o outro, entretanto nascem aqueles que assumirão os seus lugares no diálogo, uns num papel, uns em outro. (...) 


\begin{tabular}{|l|l|l|l|l|l|l|}
\hline InterteXto & Uberaba & UFTM & $\begin{array}{l}\text { v. 3 } \\
\text { n. } 2\end{array}$ & p. 62-81 & 2010 - jul. / dez. & ISSN 1981-0601 \\
\hline
\end{tabular}

Quem comparece à praça em momentos consecutivos nota que o diálogo muda de ato em ato, ainda que a vida dos habitantes de Melânia seja breve demais para que possam percebê-lo. (p. 78-79)

Os diálogos que parecem se repetir, mas que "mudam de ato em ato" representam as lentas mudanças que acontecem nas vidas das pessoas decorrentes da mudança incessante do mundo moderno. Tais modificações atravessam o tempo e ficam retidas na memória coletiva.

Porventura seja possível dizer que essa questão da memória coletiva, que não é algo estático, contrapõe-se à idéia de memória apresentada no poema "Edifício Esplendor". Enquanto não se fala em um passado determinado em As Cidades Invisíveis, mas em distintos momentos da cidade, no poema isto acontece, posto que há um eu que menciona claramente o seu passado, define-o, está retido nele. Em "Edifício Esplendor", nota-se que a memória do eu-lírico o remete a um tempo, a um passado que não poderá vir a ser igual ao presente, que não tem mais lugar no mundo de pessoas-máquinas em que se vive. Há saudade de sentimentos humanos, ainda que estes façam sofrer. Aquilo que era mobilidade transformou-se em maquinismo. O homem de agora é apático, não sofre nem vibra. A viagem do passado ao presente que a memória possibilita e que por vezes passa despercebida no espaço urbano, é trazida para a vida do indivíduo isolado por meio daquilo que faz parte da composição do ambiente em que se vive: "Há um retrato na parede,/ um espinho no coração,/ uma fruta sobre o piano/ e um vento marítimo com cheiro de peixe, tristeza, viagens.../ Era bom amar, desamar,/ morder, uivar, desesperar,/ era bom mentir e sofrer". Como é percebido neste fragmento, determinadas coisas trazem de volta a lembrança do que não mais pode ser, já que não mais existe. Se neste fragmento o passado volta, tem-se consciência dele e consciência de que ele não mais poderá se repetir, a permanência de alguns traços desse passado na vida presente explica o porquê de a mudança humana ser mais demorada, conforme representado em As Cidades Invisíveis. O tom nostálgico percebido nos versos de Drummond mostra que o que está 


\begin{tabular}{|l|l|l|l|l|l|l|}
\hline InterteXto & Uberaba & UFTM & $\begin{array}{l}\text { v. 3 } \\
\text { n. } 2\end{array}$ & p. 62-81 & 2010 - jul. / dez. & ISSN 1981-0601 \\
\hline
\end{tabular}

perdido não pode ser recuperado, não há a possibilidade de amar, desesperar de novo, pois "se acabaram os homens./ Ficaram apenas tristes moradores". Ao dizer "Chora retrato, chora" percebe-se mais fortemente esta saudade. O retrato é, de alguma forma, capaz de reter o passado. Quem chora não é o retrato, mas aquele que o vê e sabe que aquilo que ele representa é apenas uma recordação.

É possível perceber ainda no poema o desamparo que é sentido pelo eu-lírico, o morador do edifício. Ele se vê entre toda a modernidade e tecnologia, onde a funcionalidade das instalações parece convidar ao suicídio: "As complicadas instalações de gás,/ úteis para o suicídio,/ o terraço onde camisas tremem,/ também convite à morte". Símbolo maior desta tecnologia fúnebre é o elevador: "o pavor do caixão/ em pé no elevador". Como afirma Ferraz (2002, p. 64), "fechamento e descontinuidade encontram no "elevador" uma imagem síntese: sufocamento, subordinação do movimento e da vitalidade humanos à rigidez e à monotonia da máquina". Além desse desejo de se matar causado pelos avanços tecnológicos, a mudança nos costumes e nos sentimentos ("surgiram costumes loucos/ e mesmo outros sentimentos") revela um mundo mecanizado, alienado, em que para sobreviver é necessário que os sentimentos sejam adaptados à nova realidade. Esta noção de que os sentimentos e as coisas são descartáveis no mundo moderno também é retratada por Calvino em seu romance. Em certo ponto da narrativa, Marco descreve a cidade Leônia que "refaz a si própria todos os dias". Em Leônia, "uma vez que as coisas são jogadas fora, ninguém mais quer pensar nelas" (p.109). De uma forma absurda, a cidade remove os restos de sua existência todos os dias, jogando fora coisas velhas para darem lugar a coisas novas. Nada é retido, tudo é substituído incessantemente. Deste modo, a cidade se refaz a si própria ininterruptamente, sempre se vestindo de novo. Conforme Gomes (1994, p. 54), "[Leônia] é a cidade com toda parafernália do consumo de massa e dos aparatos produzidos pela indústria moderna: a cidade do descartável, que gera o enorme e cumulativo lixo desse consumo 


\begin{tabular}{|l|l|l|l|l|l|l|}
\hline InterteXto & Uberaba & UFTM & $\begin{array}{l}\text { v. 3 } \\
\text { n. } 2\end{array}$ & p. 62-81 & $2010-$ jul. / dez. & ISSN 1981-0601 \\
\hline
\end{tabular}

desenfreado". Mas, para incomodar e ameaçar Leônia que quer sempre ser novidade, o passado é conservado através do lixo, ele é a sua memória. Percebe-se, portanto, que há duas Leônias: a que sempre acorda e a que se veste de seu lixo. Quanto mais Leônia tenta apagar suas lembranças enterrando o velho, mais fortifica a Leônia que se alimenta do passado. Ainda de acordo com Gomes (1994, p. 55), esse lixo/passado acumulado representa a tradição, que ameaça a modernidade. A cidade é vítima de seu próprio desenvolvimento, pois ela "cresce na proporção do crescimento de seu lixo". Essa busca incessante pelo novo talvez evidencie a doença, a crise das cidades modernas: "- Sim, o império está doente, o que é pior, procura habituar-se às suas doenças" (p.59).

Com o conceito de memória como tradição, perpetuação de valores, que, por mais que se deseje manter distantes continuam a assombrar a existência no espaço urbano, tem-se, de algum modo, a confirmação de que, no poema "Edifício Esplendor", o eu-lírico é tomado por um sentimento nostálgico, quer dizer, por mais que ele construa e viva num mundo com muitas novidades, sempre há a sombra, há fantasmas do passado, valores e lembranças que voltam para assombrá-lo: "Meu pai, meu avô, Alberto..../ Todos os mortos presentes (...)/ Os mortos olham-se e calam-se". Por outro lado também, ao entender a memória como tradição, volta a idéia apresentada em As Cidades Invisíveis de uma memória coletiva que está sempre lá, por mais que se tente escondê-la, guiando, regendo, tomando conta de todos os passos e, de alguma forma, permitindo que o mundo de máquinas em que se vive seja construído sobre a ilusão de que é totalmente novo, de que não retém algo de seus momentos passados. A dicotomia "novo vs. memória" percorre o livro em inúmeras ilustrações. Ao mesmo tempo que se deseja recomeçar, esquecer o passado, mais ele é trazido à tona pela lembrança.

Porém, a questão relativa à memória em As Cidades Invisíveis não se limita à noção de memória coletiva. A esta se aliam outras noções. O perder-se nas cidades descritas por Marco Polo é devido ao fato de que uma lembra e faz 


\begin{tabular}{|l|l|l|l|l|l|l|}
\hline InterteXto & Uberaba & UFTM & $\begin{array}{c}\text { v. } 3 \\
\text { n. } 2\end{array}$ & p. 62-81 & $2010-$ jul. / dez. & ISSN 1981-0601 \\
\hline
\end{tabular}

compreender a outra. Num diálogo entre Marco Polo e o Khan, observa-se a explicação de Marco acerca desta lembrança de outras cidades:

- Parece que você conhece melhor as cidades por meio do atlas do que visitando-as pessoalmente - disse o imperador a Marco, fechando o livro de repente.

E Polo:

- Viajando percebe-se que as diferenças desaparecem: uma cidade vai se tornando parecida com todas as cidades, os lugares alternam formas ordens distâncias, uma poeira informe invade os continentes. O seu atlas mantém intatas as diferenças: a multiplicidade de qualidades que são como as letras dos nomes. (p. 131)

Nas palavras de Gomes (1994, p. 58), "a nomeação da cidade é que the dá existência, concretizando o modelo que Marco Polo diz ter imaginado e de que extrai todas as outras cidades”. O nome é a única coisa que dá às cidades modernas a sua identidade, uma vez que são contínuas, espelhos umas das outras e se perdem no mundo. À semelhança dos grandes centros contemporâneos, nas cidades de Calvino não há diferença na paisagem, há apenas prédios que enclausuram, crescem, aprisionam os indivíduos que neles habitam ("As famílias se fecham em células estanques"). Paradoxalmente, Calvino, na voz de Marco Polo, mostra que para cada indivíduo / cidadão, há um modelo de cidade, do qual as outras se aproximam ou distanciam. Gomes (1994, p.58) aponta o fato de que para os modernistas "as cidades são sempre uma e a mesma cidade". O próprio Marco Polo ao ser questionado por nunca mencionar Veneza afirma: "Todas as vezes que descrevo uma cidade digo algo a respeito de Veneza" (p.84). Ele jamais menciona Veneza, sua cidade natal, porque ela está implícita em todas as outras de que ele fala. Ao falar de cada cidade, a primeira que lhe vem à mente é a sua. Ao mencionar implicitamente Veneza, ele não sabe se esta é uma forma de mantê-la viva ou de apagá-la, pois ao misturá-la às outras, ela perde um pouco de seu diferencial, deixa de ser especial, dissolve-se e torna-se parte de um imaginário comum de cidade, 


\begin{tabular}{|l|l|l|l|l|l|l|}
\hline InterteXto & Uberaba & UFTM & $\begin{array}{c}\text { v. } 3 \\
\text { n. } 2\end{array}$ & p. 62-81 & 2010 - jul. / dez. & ISSN 1981-0601 \\
\hline
\end{tabular}

mas, possivelmente o fato de nunca mencionar seu nome seja também uma tentativa de preservá-la, retê-la: “- As margens da memória, uma vez fixadas com palavras, cancelam-se - disse Polo. - Pode ser que eu tenha medo de repentinamente perder Veneza, se falar a respeito dela. Ou pode ser que, falando de outras cidades, já a tenha perdido um pouco" (p. 85).

As cidades possuem um ritmo próprio, crescem, incham, fogem ao previsível. Portanto, ao criar um modelo de cidade feita somente de diferenças, como propõe Marco Polo, e a partir disso descrever outras cidades que fogem mais ou menos a esse modelo, constrói-se a idéia de que para cada cidade que é, que existe, há inúmeras outras possibilidades do que elas poderiam ter sido: "Dentro de cada esfera, vê-se uma cidade azul que é o modelo para uma outra Fedora. São as formas que a cidade teria podido tomar se (...) não tivesse se tornado no que é atualmente" (p.34)

Esse aspecto das cidades modernas como cidades contínuas, que não possuem início e nem fim, diferenciando-se apenas de nome no aeroporto (cf. p.123), está intimamente ligado à questão do superpovoamento das grandes cidades. Em cidades populosas, perdem-se os referenciais, há uma homogeneização. Exemplo disso é a cidade Procópia, que com o passar dos anos torna-se mais e mais povoada. A cidade incha-se a ponto de amedrontar as pessoas, deixando-as sem espaço para se moverem. Há uma falta de ar, um incômodo constante:

Todos os anos nas minhas viagens faço escala em Procópia e hospedo-me no mesmo quarto da mesma pensão. (...) Assim, ano após ano, vi o desaparecimento do fosso, da árvore, do espinhal, escondidos por barreiras de sorrisos tranqüilos em caras redondas que se movem mastigando folhas. Não se tem idéia, num espaço limitado como o da plantação de milho, de quanta gente ela pode conter, especialmente se postos sentados com os braços em torno dos joelhos, imóveis. (...) No meu quarto, somos vinte e seis pessoas: para mover os pés, preciso incomodar os que estão agachados no chão, abro espaço entre os joelhos daqueles sentados sobre a cômoda e os cotovelos daqueles que se revezam para se apoiar na cama. (pp. 139-140) 


\begin{tabular}{|l|l|l|l|l|l|l|}
\hline InterteXto & Uberaba & UFTM & $\begin{array}{l}\text { v. 3 } \\
\text { n. 2 }\end{array}$ & p. 62-81 & 2010 - jul. / dez. & ISSN 1981-0601 \\
\hline
\end{tabular}

Esse sentimento de enclausuramento é parecido com o do eu-lírico em "Edifício Esplendor": "O elevador sem ternura/ explode, absorve/ num ranger monótono/ substância humana (...)/ o pavor do caixão/ em pé no elevador".

Essa falta de espaço para os seres humanos é responsável pelo alargamento das cidades, unindo-as, transformando-as num grande bloco de cidades sem direção clara. Este processo é retratado em Pentesiléia, que não possui orientações claras, é vaga, labiríntica como toda grande cidade moderna: "Fora de Pentesiléia existe um lado de fora? Ou, por mais que você se afaste da cidade, nada faz além de passar de um limbo para o outro sem conseguir sair dali?"(p. 151). Gomes (1994, p. 57) atenta para o fato de que este tipo de cidade é "a megalópole sem exterior, policentrada, labiríntica, difícil de ser reconhecida e recordada".

Ao entender as cidades como labirintos de onde não há saída, como lugares sufocantes, tem-se a impressão de que se está no inferno, pois não há como sair, fugir, há pessoas por todos os lados, não há espaço. Por estarem unidas graças ao acaso, as pessoas desejam o isolamento. Porém, este é triste, infeliz, incômodo. Sendo assim, ao mesmo tempo que não se quer as pessoas, é preciso tê-las. Essa confusão de sentimentos e sensações permite a conclusão de que estar numa cidade grande é estar num inferno. Conviver com pessoas e com a memória é estar num inferno. A este respeito, Marco, por fim, diz a Kublai Khan:

- O inferno dos vivos não é algo que será; se existe, é aquele que já está aqui, o inferno no qual vivemos todos os dias, que formamos estando juntos. Existem duas maneiras de não sofrer. A primeira é fácil para a maioria das pessoas: aceitar o inferno e tornar-se parte deste até o ponto de deixar de percebê-lo. A segunda é arriscada e exige atenção e aprendizagem contínuas: tentar saber reconhecer quem e o que, no meio do inferno, não é inferno, e preservá-lo, e abrir espaço. (p. 158)

Marco, neste fragmento, faz um questionamento acerca da vida em comunidade e do futuro da humanidade. Inferno é aquilo que se constrói 


\begin{tabular}{|l|l|l|l|l|l|l|}
\hline InterteXto & Uberaba & UFTM & $\begin{array}{l}\text { v. 3 } \\
\text { n. } 2\end{array}$ & p. 62-81 & 2010 - jul. / dez. & ISSN 1981-0601 \\
\hline
\end{tabular}

vivendo junto. Como Marco aponta, a forma mais otimista de se continuar existindo seria através da insistência e da resistência, da busca por aquilo que não é inferno. Entretanto, o caminho mais fácil é o da resignação, é aceitar o inferno e deixar de percebê-lo. Porém, por não ser o caminho mais satisfatório, não se sabe até quando será possível aceitar a realidade passivamente. A insubordinação humana, desta forma, parece indicar que Calvino a apresenta como a chave mestra para um futuro diferente, menos mecanizado.

Ao pensar no inferno, destruição, não há como não pensar na imagem que fecha o poema de Drummond: "- Que século, meu Deus! Diziam os ratos./ E começavam a roer o edifício". Essa imagem do rato como elemento de destruição, de fim, também aparece algumas vezes em "As Cidades Invisíveis":

Nos séculos de degradação, a cidade, esvaziada por causa das pestilências (...) repovoava-se lentamente com hordas de sobreviventes emersos de sótãos e covas como férvidos ratos movidos pelo afã de revolver e roer e que ao mesmo tempo se reuniam e se ajeitavam como passarinhos num ninho. (p.102)

E também, na descrição da penúltima cidade, Teodora: "Mas antes disso, por longos anos, permaneceu incerto se a vitória final não seria da última espécie a prosseguir disputando com os homens a posse da cidade: os ratos" (p.152).

A figura do rato no poema de Drummond, como aponta Ferraz (2002), é uma crítica contundente à modernidade, já que o edifício, metáfora da cidade moderna, a si mesmo destrói. Percebe-se que, de algum modo, o mesmo ocorre nas citações acima de As Cidade Invisíveis. Na primeira, há a comparação de homens com ratos, animais que consomem os restos, ficam com as sobras representando a degradação, o mal. Na segunda citação, percebe-se a disputa da cidade entre homens e ratos, ou seja, qual dessas espécies resistirá a toda devastação, ao inferno que as cidades modernas produzem? Seja como for, tanto no poema quanto no romance, não se consegue enxergar otimismo em relação ao futuro. Parece que o mundo 


\begin{tabular}{|l|l|l|l|l|l|l|}
\hline InterteXto & Uberaba & UFTM & $\begin{array}{l}\text { v. 3 } \\
\text { n. } 2\end{array}$ & p. 62-81 & 2010 - jul. / dez. & ISSN 1981-0601 \\
\hline
\end{tabular}

caminha em direção à própria destruição. Calvino olha criticamente para as cidades do século $X X$, enquanto Drummond transforma o século $X X$ em um edifício que tem como seu coração a máquina, mostrando o fim da utopia moderna ${ }^{4}$. Talvez o olhar do poeta e do escritor, como pessoas sensíveis, descortine um futuro que, para as pessoas comuns, ainda é nebuloso.

\section{Considerações finais}

Após estes comentários a respeito do romance As Cidades Invisíveis, de Ítalo Calvino, e o poema "Edifício Esplendor", de Carlos Drummond de Andrade, faz-se necessário tecer algumas observações finais acerca do que foi apresentado.

De acordo com Bueno (2002, p. 233-234), os grandes escritores da modernidade, com destaque para Drummond e Calvino, têm em comum o fato de oferecerem "o exame atento e cuidadoso, irônico e amoroso, racional e sensível, da condição humana vivida no contexto da cidade e da metrópole capitalista e contemporânea". Esses escritores possuem um olhar de certa forma distanciado da realidade, como se não fizessem parte dela. São capazes de perceber detalhes da vida moderna no século $X X$ que, por vezes, passam despercebidos. Por isso, a leitura de suas obras permite a apreensão de certos detalhes da realidade muito próxima em que se vive.

Em As Cidades Invisíveis, Calvino apresenta um diálogo imaginário entre Marco e Kublai ${ }^{5}$, extrapola os limites da realidade e transporta para o século XIII características camufladas das cidades do século XX. Calvino consegue combinar nesta obra os princípios por ele considerados indispensáveis para a literatura no século XXI: leveza, rapidez, exatidão, visibilidade e multiplicidade (cf. Calvino, 2000).

\footnotetext{
${ }^{4}$ Notas das aulas da disciplina "Escrita e Experiência Urbana", ministrada pelo professor Eucanaã Ferraz no segundo semestre de 2003.

${ }^{5}$ De acordo com os registros históricos, no século XIII, após uma viagem que teria durado trinta meses, o mercador veneziano Marco Polo chegou ao Extremo Oriente e conheceu a capital do grande império de
} 


\begin{tabular}{|l|l|l|l|l|l|l|}
\hline InterteXto & Uberaba & UFTM & $\begin{array}{l}\text { v. 3 } \\
\text { n. } 2\end{array}$ & p. 62-81 & 2010 - jul. / dez. & ISSN 1981-0601 \\
\hline
\end{tabular}

A obra de Calvino não trata apenas de um jogo de percepções confusas, um obstáculo ao conhecimento da realidade, mas de uma "utopia consciente", da imaginação que não tenta fugir da realidade, mas que a encara ao seu jeito (Bueno, 2002, p. 244). Calvino constrói outra maneira de perceber a vida nas cidades, mas isso não significa que ele tenha a intenção de mudá-la. Paralelo a Calvino, nota-se que Drummond também parece enxergar a realidade brasileira de forma parecida. Ele dá um sentido complexo às tensões históricas e sociais do país: passado e presente, modernização e atraso. Enfim, Drummond possui uma imaginação criadora muito potente e um conhecimento profundo do cotidiano no mundo e na cidade.

Por fim, resta dizer que o conhecimento urbano compartilhado por Calvino e Drummond denuncia certo pessimismo quanto ao passado (século $X X$ ), ao presente (século XXI) e, possivelmente, ao futuro dos centros urbanos. Contudo, apesar de caóticas, as cidades são fascinantes e, quanto mais observadas em sua complexidade, mais encantadoras se tornam.

\section{Referências}

ANDRADE, Carlos Drummond de. Sentimento do Mundo. Itabira, Edição do autor, 1940.

ARGAN, G. "Crise da arte, crise do objeto, crise da cidade" In: ARGAN, G. História da arte como história da cidade. São Paulo: Martins Fontes, 1998 (pp. 211-269)

. "Cidade ideal e cidade real" In: ARGAN, G. História da arte como história da cidade. São Paulo: Martins Fontes, 1998 (pp. 73-84)

BERMAN, M. "Introdução: Modernidade ontem, hoje e amanhã" In: Tudo que é sólido desmancha no ar. A aventura da modernidade. Trad. Carlos Felipe Moisés e Ana Maria L. Ioriatti. São Paulo: Companhia das Letras, 1992 (pp. 15-

Kublai Khan: Cambaluc, Pequim, nos dias de hoje. Marco permaneceu por lá durante 17 anos desempenhado importantes funções diplomáticas (Caderno cultural do jornal "Folha de S. Paulo", 2003). 


\begin{tabular}{|l|l|l|l|l|l|l|}
\hline InterteXto & Uberaba & UFTM & $\begin{array}{l}\text { v. 3 } \\
\text { n. } 2\end{array}$ & p. 62-81 & 2010 - jul. / dez. & ISSN 1981-0601 \\
\hline
\end{tabular}

35)

BUENO, A. "Sinais da cidade: forma literária e vida cotidiana". In: BUENO, A. Formas da crise: estudos de literatura, cultura e sociedade. Rio de Janeiro: Graphia, 2002. (pp. 213-233) . "Literatura e vida nas cidades: os sentidos da imaginação". In: BUENO, A. Formas da crise: estudos de literatura, cultura e sociedade. Rio de Janeiro: Graphia, 2002. (pp. 234-244)

CALVINO, I. (trad. MAINARDI, D.) As Cidades Invisíveis. Rio de Janeiro: O Globo, 2003. . ( trad. BARROSO, I.) Seis Propostas para o Próximo Milênio. $2^{\mathrm{a}}$ ed. São Paulo: Cia. das Letras, 2000.

FERRAZ, E. "O poeta vê a cidade". In: Poesia Sempre, n.16, Rio de Janeiro: Biblioteca Nacional, out. 2002.

GOMES, R. C. Todas as Cidades, a Cidade. Rio de Janeiro: Rocco, 1994. 